\title{
Adjusting to bodily change following stoma formation: A phenomenological study
}

\author{
Abstract \\ Purpose: Scant research has been undertaken to explore in-depth the meaning of bodily \\ change for individuals following stoma formation. The aim of this study was to understand \\ the experience of living with a new stoma, with a focus on bodily change.
}

Method: The study adopted a longitudinal phenomenological approach. Purposeful sampling was used to recruit twelve participants who had undergone faecal stoma-forming surgery. Indepth, unstructured interviews were conducted at three, nine and fifteen months following surgery. A five-stage framework facilitated iterative data analysis.

Results: Stoma formation altered the taken-for-granted relationship individuals had with their bodies in terms of appearance, function and sensation, undermining the unity between body and self. Increasing familiarity with and perceived control over their stoma over time diminished awareness of their changed body, facilitating adaptation and self-acceptance.

Conclusions: Stoma formation can undermine an individual's sense of embodied self. A concept of embodiment is proposed to enable the experience of living with a new stoma to be understood as part of a wider process of re-establishing a unity between body, self and world. In defining a framework of care, individuals with a new stoma can be assisted to adapt to and accept a changed sense of embodied self. 


\section{Introduction \& Background}

Approximately 102,000 individuals live with an excretory stoma in the UK, with around 21,000 individuals undergoing stoma-forming surgery each year [1]. For America, the equivalent figures are over $1,000,000$ and 130,000 respectively [2]. A stoma is a surgically constructed opening into a hollow organ. This paper focuses on colostomy, an opening into the large bowel or colon and ileostomy, an opening into the distal small bowel or ileum. Colostomies and ileostomies are created to redirect the contents of the bowel to the abdomen, where they empty into an appliance. The most obvious disruption of bodily function following stoma formation is that the faecal elimination function of the body is changed from sitting on the toilet to pass a motion to being required to empty and/or change a stoma appliance. People most commonly require bowel stoma-forming surgery for rectal cancer, ulcerative colitis, Crohn's disease or diverticular disease [3].

\section{Previous studies of health-related quality of life $[4,5,6,7]$ in people receiving stoma-forming}

surgery and one meta-synthesis [52] have found that stoma-forming surgery has a dramatic impact on post-operative adjustment in terms of poor self-image and individuals feeling out of control of their bodies and their lives. However, a deeper understanding of meaning to those experiencing stoma formation has been largely absent.

Qualitative research findings have been chiefly concerned with experiences of bodily change, as indicated in a previous interpretive review of the literature undertaken to inform this research [8]. Specifically, awareness of a changed body [9], living with bodily changes [10], alienation from the body [10,11] and altered body image [11]). In other studies the experience of bodily change has been described in broad themes relating to loss of wholeness [12], practical stoma management [9, 13,14], self-care [15], adapting to change [16], personal control $[17,18]$ and feeling different [19]. Profound feelings of self-deprecation and self-hatred, with reactions of shock, disgust and repulsion are not uncommon among people after undergoing stoma-forming surgery $[20,21,15,10,13,11]$. Alienation or distance from the body may be experienced $[22,9,13,19]$. 
Concerns relating to bodily appearance include the distress of looking at the stoma for the first time, general stoma appearance and changes in overall bodily appearance $[20,23,22$, $9,15,11]$. Kelly [9] explored how awareness of disrupted bodily appearance in these ways can disrupt a person's sense of self. Others also identify the appearance of the appliance or the experience of a filled stoma bag as engendering heightened feelings of selfconsciousness $[16,11,19]$.

Sensory changes can also be experienced, such as the uncontrolled sound of flatus passing through the stoma or the smell of the content of the bowel as the appliance is changed or emptied, if it leaks or if the appliance filter fails $[20,12,13,11,16]$. Awareness that the stoma has worked and that the appliance needs emptying or changing can be deeply distressing and embarrassing [16].

Changes to bodily function are often connected to feelings of control. Sutherland et al [20], Kelly [90], McVey et al [17], Rozmovits and Ziebland [14] and Annells [18] all identify a feeling of loss of control related to the particular problems caused by unprompted and unexpected faecal or flatus output from a stoma and the experience of appliance leakage. Some studies highlight the importance of the individual's ability to cope with and limit disrupted bodily function, including not just routine practical stoma care, but the management of stomal complications and the contribution of diet to stoma function $(18,22]$. The level of support individuals are given to achieve this influences their perceived control over and adjustment to their stoma $[9,13,17,11]$.

The experience of bodily change is shown to be fundamental to living with a stoma. Although some studies have identified different aspects of bodily change there has been a lack of conceptual clarity. This limits the way in which current understanding of experience of stoma formation can offer something for patients and those who care for them. Others use the concept of body image when interpreting data, but are at risk of overlooking the broader changes that a person may experience [13, 11,19]. Orbach \& Tallent [21], Kelly [9] and 
Manderson [16] offer a more in-depth exploration of subjective bodily change following stoma formation. Orbach and Tallent [21:126] have highlighted, "a revision of perceived body and of body concepts," but do not explore the relationship between body and self. Kelly [9:394] defines self as "an imaginative view of ego by ego." This definition seems to fit well with a concept of body image, but Kelly's detailed exploration of the experience of ileostomy formation appears to embrace the concept of an integrated, embodied self [9].

These findings highlight a need for more robust, in depth research examining the experience of bodily change following stoma-forming surgery and a revised conceptual framework through which changes to a person's sense of embodied self, rather than just their body image, can be explored and understood. Body image as a concept is poorly defined in understanding the experience of people undergoing stoma-forming surgery [43]. Many authors [11, 43, 44] refer to a definition offered twenty years ago by Price [45, 46:14]: "the picture we form in our minds of how our body looks, and the experience we have of how our body feels, behaves and conforms to commands we give it." Within Price's definition the term 'picture' implies something that is being looked 'at' rather than lived and experienced pre-reflectively as part of the self and so potentially limits understanding of the experience of a disrupted lived body that occurs following this surgery. Merleau-Ponty [27] described the lived body as the body that is experienced pre-reflectively, unconsciously taken for granted in everyday life and forming a unity with the mind to create an individual's sense of embodied self. The notion of the embodied self and the resultant concept of 'embodiment' have been used by researchers and academics to deepen understanding of bodily change stemming from illness and disability in a number of disciplines [47, 48]. IIIness and disability bring the lived body into conscious consideration by changing its appearance, sensation and function and making it unfamiliar, even alien, to the individual [49]. Using a concept of embodiment, the process of adjusting to the bodily changes instigated by many health conditions, including stoma formation, can be understood as part of a wider process of reestablishing a unity between body, self and world. This understanding enables those who 
provide paid and unpaid care to gain deeper insight into the experiences of their patients

and consequently the opportunity to provide more sensitive and individualised care for them.

\section{Aim}

The aim of the study was to explore the experience of living with a new stoma. Findings from the study relating to the impact of professional care on the experience of living with a new stoma have been previously reported [24]. This paper focuses on experiences of bodily change following stoma formation and identifies embodiment as a conceptual framework that goes beyond body image to more accurately represent this profound experience.

\section{Methodology}

Phenomenological qualitative research aims to explore and understand phenomena events, things, problems - in the manner in which they appear to the individual experiencing them [25]. It constitutes both a philosophy and research approach underpinned by the notion that the world is subjectively and consciously experienced, and made real for individuals through the meaning they derive from their experience of it [26]. The focus of the research was to explore more deeply how individuals experience the profound change to their lived bodies created by stoma formation and the multiple ways in which this could impact on their being-in-the-world [27]. Existential phenomenology was chosen to capture a more universal understanding of participants' experiences using a process of abstraction in which the essential structures of the experience are identified and described.

\section{Study design}

Time-points of three, nine and fifteen months were selected to explore individuals' experiences. At three months, participants could be expected to have recovered physically from the surgery to a sufficient extent to be involved in an in-depth interview and be able to engage with its purpose, which may not have been the case at an earlier time-point [23]. Time-points of nine and fifteen months could explore adjustment to a new stoma over time and re-examine the proposition that adjustment to a stoma is complete by one year postsurgery $[28,29,30,6]$. 
The research site was a large district general NHS teaching hospital in the UK, at which over 300 surgical procedures involving stoma formation were undertaken each year for a wide range of clinical conditions.

\section{$\underline{\text { Sample }}$}

Illness history, diagnosis and mode of presentation for surgery are factors that may contribute to the experience of living with a stoma $[31,5]$. Therefore, a maximum variation purposive sampling strategy was used to facilitate the recruitment of individuals with different diagnoses, illness histories and modes of presentation [32]. A sample size of twelve participants, interviewed three times each, would provide sufficient data to gain insight into multiple, varied perspectives regarding the experience of stoma formation, while retaining the ability to achieve a full, in-depth exploration of each individual experience. The adequacy of this sample size was supported by the ability to identify the essence of the experience of living with a new stoma from the data collected.

Selection criteria for patient participants were guided by the longitudinal design of the study, underpinning diagnoses leading to stoma formation and the specific nature of faecal stoma formation as shown in table one. Capturing insight into the experience of living with a temporary stoma was considered an important part of the research aim and so people with a temporary stoma were not excluded. However, individuals were required to have a stoma for at least the first two interviews in order to ensure sufficient experience of the phenomenon.

Insert Table 1 here: Inclusion and exclusion criteria

\section{$\underline{\text { Recruitment }}$}

Participants were recruited through a gatekeeper, the lead colorectal specialist nurse at the research site, who provided prepared participant information packs to all individuals who met the study selection criteria. Recruitment was undertaken at monthly intervals over four months.

Twelve participants were recruited with variation achieved in underlying diagnosis, age, 
nature of presentation for surgery and stoma type (table 2).

Insert Table 2 here: Demographic and surgery-related factors in recruited participants

Craig and David had their stomas unexpectedly reversed prior to nine months following their

surgery and were therefore ineligible to continue to participate. One further participant,

Greta, was lost to follow-up for her final interview. Data already collected from these

participants were used to inform research findings.

\section{Data collection}

One-to-one interviews were chosen as the method of data collection that would most effectively enable the capture of individual, lived experience. An open-ended, conversational interview approach was used [32]. A single question focused participants on their experience of living with a stoma: "please can you tell me about your experience of living with a stoma?" This was followed by exploratory open questioning and probes based entirely on the issues and experiences they were prepared to share with the interviewer (GT), therefore enabling the participants to control the direction of the interview [33]. As the researcher conducting the study (GT) had prior clinical experience as a colorectal and stoma care specialist nurse, this approach was important in minimising her influence on the interview data generated. She was also interviewed herself prior to data collection to increase self-awareness of preconceptions regarding the research topic [34]. Participants were not previously known to the researcher or informed of the researcher's clinical background.

Informed consent was obtained prior to each interview. Following each interview any reflections and observations pertinent to the research process were recorded in a research diary along with thoughts about the data and emerging interpretations that could be used during data analysis. It also provided an opportunity to note down thoughts and reflections about ways in which data might be influenced by the questioning style and relationshipbuilding with participants, and/or emotional responses to participants' experiences. Awareness of and reflection on these issues reflexively was used to foster strategies to build 
into the interview approach to optimise subsequent data collection. All participants chose to be interviewed in their own home. Interviews lasted between 40 and 90 minutes and were digitally audio-recorded and transcribed verbatim.

\section{Data analysis}

The analytical framework was guided by a synthesis of established methods of analysis, in particular Colaizzi [35], van Manen [36] and Smith and Osborn [37]. These approaches informed the analytical framework design, allowing consideration and inclusion of specific details that would be coherent with the underpinning philosophical stance, such as using existential categories to refine analysis and embracing interpretation as an integral part of the analytical process. In accepting the influence of hermeneutics on the implementation and interpretation of the research [36], a conceptual framework was used to first gain a global sense of the entire experience of each individual before embarking on a detailed scrutiny of interview data to explore in greater depth the distinct but interrelated parts of the experience.

Analysis (undertaken by GT) consisted of five stages (figure 1). The first two stages comprised a first-person narrative summary - the whole - and a deconstruction of the experience into individual words and phrases that signified meaning - the parts (37]. An interpretive reconstruction of individual accounts began in the third stage, relating to the categories of 'life-world existentials' [36]: corporeality (lived body), relationality (lived other), spatiality (lived environment) and temporality (lived time). Meaning units that did not obviously 'fit' were not assigned to a category until additional meaning units provided clarity or until later in the analytical process when more distinct codes and categories began to emerge. The existential categories were further organised and abstracted in the fourth stage. In the final (fifth) stage of analysis, emerging categories were explored across all participant accounts to facilitate the abstraction of the essential structures of the experience of living with a new stoma. Although presented in stages, the analytical framework was used iteratively, to allow movement backwards and forwards between stages, in order that interpretations could be checked against verbatim data and developing themes and modified 
accordingly [37]. These iterative cycles were considered essential to the trustworthiness of the findings.

Insert Figure 1 here: Analytical framework with worked example. Analytical framework reproduced with permission from International Journal of Nursing Studies 51, 3, 379-389 (2014). Copyright 2014, Elsevier.

Angen [38] highlights the need for equity within interpretive inquiry as a factor in establishing trustworthiness. Ambiguity or differences within individual participants' voices were used to challenge and refine emerging categories and themes, rather than disregarding any unique perspectives that had been uncovered. MM independently co-analysed a sample of selected transcripts to explore the resonance of differing interpretations.

\section{$\underline{\text { Interpretive sharing }}$}

Interpretations were shared with participants at the end of data collection, to avoid inadvertently distorting their perspectives on their own experiences; participants were invited to join a larger patient group, within which they would be unidentifiable, to view a presentation of initial findings. Members of this group were encouraged to offer written or verbal feedback. However, this did not reveal any additional perspectives to inform the interpretation of findings.

\section{Ethical approval}

This study gained approval from the research Governance Committee covering the research site on $8^{\text {th }}$ June 2007 (2007GSUR04S) and from the local Research Ethics Committee on $16^{\text {th }}$ August $2007(07 / \mathrm{H0310/94)}$. Data collection was undertaken between October 2007 and February 2009.

\section{Findings}

Insert Figure 2 here: Diagrammatic representation of study findings relating to bodily change 
The impact of stoma-forming surgery on individuals' sense of embodied self was demonstrated through a heightened awareness of their changed bodies. Illness, surgery and stoma formation experienced by participants brought into focus the relationship between body and self that had previously been experienced unconsciously. This bodily awareness could be characterised in three ways: changes in appearance, disruption of function and altered sensation, illustrated in figure 2. Following surgery, participants experienced their bodies as unfamiliar and uncontrollable. They had an expectation that time would bring renewed bodily strength and functioning, familiarity with their new circumstances and confidence to face the world again with a stoma but were uncertain about how and when this would happen. Participants' quotations are identified by pseudonym and interview time-point (e.g. Hazel, $3 m=$ a quotation from Hazel's interview at 3 months following surgery).

\section{Changes in bodily appearance}

Stoma formation changed the appearance of participants' bodies, clothed and unclothed, brought about by the stoma itself, the stoma appliance and abdominal wounds. At three months, participants described a feeling of shock and horror at the thought of having a stoma, viewing their stoma as deeply unattractive. Andrew thought he would be "an invalid for the rest of my life" $(3 \mathrm{~m})$ and repeatedly referred to feeling 'demeaned' by his stoma in all three interviews, describing how he covered his stoma as quickly as possible during an appliance change to avoid looking at it. Greta and Hazel found their change in appearance deeply distressing at times:

"well, you do feel mutilated really - you look down and here is this horrible thing, which looks like a sea anemone on top of Glastonbury Tor" (Greta, 3m).

However, even early on, familiarity facilitated acceptance: "to start with, it was strange to look at the stoma, but you get used to it and it's just part of me now" (Laura, 3m).

Despite their acceptance of the appearance of the stoma itself, some participants drew attention to the shape of their abdomen around the stoma having changed, either 
permanently or in bulging out when passing a motion: "the only thing I don't like about it is the lump; I mean, the actual red stoma bit doesn't bother me; I think that's the actual shape of my stomach since they've done it" (Ellen, 9m). At nine months, Hazel referred to the fact that she still felt disfigured by her stoma, while Greta and Hazel both described their stomas as "Vesuvius," a metaphor capturing the physical protrusion and the potentially explosive eruption of the stoma. Greta attempted to explain her feeling of "mutilation" at nine months as being a combination of her protruding abdomen around the stoma and "the actual rearrangement thing down at the bottom end" (Greta, 9m). Greta's experience highlights the impact of her stoma formation on her 'rearranged' bodily function. At fifteen months, Flora had seemingly accepted that her changed appearance would not resolve: "I've got a bulge and you can't do anything about it so you've got to put up with it" (Flora, 15m).

For some participants the appearance of their appliance played a greater part in contributing to a sense of changed bodily appearance than the appearance of their stoma. At three months, David was increasingly aware of the sight of the appliance on his body: "I think seeing it all hanging there is worse than actually just seeing the stoma with nothing round it." In contrast, Jack's previous experience of seeing his mother's cumbersome stoma appliance meant that more modern appliances pleasantly surprised him. Laura also imagined the appliances to be bigger and more unsightly. The appearance of their stoma appliance continued to trouble some participants at nine and fifteen months. Andrew and Hazel avoided looking at themselves in the mirror with the appliance attached, as this reminded them of their changed bodily appearance and function,

“I don't look in the mirror so much [as I used to]; always having that thing stuck on you it's not nice" (Hazel, 15m)

For others it was not the look of the appliance to themselves but the thought of others seeing it that they sought to avoid: 
“I don't think that's nice for other people to see such a thing ... you wouldn't feel comfortable walking around showing your tummy off with a bag on" (Jack, 9m)

An alteration in clothed bodily appearance impacted strongly both on participants' sense of self and on their relationship with others, with the appliance thought to be visible beneath clothing. For some, the way they dressed was changed to disguise this. For Maria, looking to others as she did pre-operatively was a vital part of how she coped with her stoma:

“I wasn't concerned about what it would look like to me because l've got stretch marks and saggy boobs and it ain't as if I've got a body that was all that lovely anyway, so all I was worried about was how can I wear things so nobody else could see it." (Maria, 3m)

Participants also talked about buying new clothes on the basis of what was felt appropriate to wear with a stoma, rather than a style they would previously have chosen. Hazel described feeling less attractive and less like a woman as she felt that she had to wear big tops in big underwear and baggy tops. At nine and fifteen months, most felt more confident about their choice of clothing as abdominal discomfort and swelling started to diminish and they took an interest once again in feeling good in what they were wearing.

\section{Disruption of bodily function}

General bodily function and its impact on participants' ability to undertake activities of daily living featured at length in participants' initial experiences of stoma formation. Impaired mobility and depleted energy levels were largely attributable to abdominal and perineal pain and surgical complications. These experiences of disrupted bodily function were vastly intensified by stoma formation, requiring participants to cope with an alien bowel function, requiring construction of a new normality for each individual. A sense of control over stoma function was influenced by: consistency of stoma output, predictability of stoma function, ability to master stoma self-care and experiences of appliance leakage. 
For most participants, stoma function settled within nine months following surgery and participants were able to construct a routine with their stoma that facilitated a sense of bodily mastery and boosted their confidence and ability to return to a wider social life. Many participants talked positively about how much easier it was to develop a "pattern of everyday life" (Andrew, 9m) with a stoma that worked in a predictable way. However, five participants experienced an unsettled and unpredictable stoma output. At three months, this was partly attributed to post-operative chemotherapy for Laura and Hazel and active small bowel Crohn's disease for Bob. By nine and fifteen months, participants who continued to live with an unsettled stoma output had developed a way to limit the impact this had on their lives. Ellen talked about making sure she had extra appliances when she went out, Bob emptied his appliance before travelling any distance and several had deduced which foods would change the consistency of their outputs, enabling them to make informed choices about diet. In contrast, Flora and Hazel's experience of erratic stoma function at fifteen months hampered their progress towards a feeling of bodily mastery:

"if I knew when I was going that would be perfectly all right, at least l'd be able to say "well I'm going in the morning, l'm going at night" but not knowing, that's the hardest thing" (Hazel, 15m).

Passing wind from the stoma accentuated feelings of loss of control. In returning to the social activities they enjoyed prior to stoma formation, fear of passing wind from their stoma was greater for some participants than passing a motion, although most appeared to worry about this less by nine and fifteen months.

Mastery of the stoma involved learning about stoma self-care, appliance management and being able to cope practically with appliance leakage. The ability to look after the stoma was related to the level of support received and emotional 'readiness'. During the initial days some felt unable to take responsibility to care for their stoma as they were still coming to terms with the emotional and physical disruption of major bowel surgery. Ken and Laura 
described being asked to deal with their stomas when they did not feel emotionally ready. Flora felt very apprehensive at the thought of having to take responsibility for her own stoma care,

"You can lay back and think of England when somebody is cleaning you up and taking away the mess and the horror and making you feel much better and clean and a nice bag on and everything, that's lovely ... but then comes the day when you have to try and do it yourself, under supervision, and that was a bit scary." (Flora, 3m)

The transition between being cared for and becoming self-caring was experienced in different ways. Some were shown how to care for their stoma and change their appliance just once and then felt able to continue this independently, either through choice,

"I didn't want no-one else there, I wanted to do it on my own so me and my husband did it, we changed the bag ourselves in the morning before she (stoma care specialist nurse) came" (Maria, 3m),

or because professional support had not been available when required, "you were left to your own devices so I suppose that's why I just sort of got up and got on with it" (Ellen, 3m). Although a lack of professional support fostered a drive for independence in some, it left others feeling abandoned. For David, the thought of having to deal practically with his stoma felt so overwhelming that he relied entirely on his wife until several weeks after he returned home:

"I didn't really take a lot of notice of it until we came home; I just went into the toilet and she (my wife) came with me and she just done it all; I just sat on a chair and didn't even look at it" (David, 3m).

At nine months many participants felt a sense of mastery over their stomas: "once I got used to what I had to do and once I got the product that suits me l've had no problems" (Ken, 9m). 
With little knowledge of stoma products participants felt dependent on the stoma care specialist nurses to provide them with the most appropriate appliance and to teach them how to use it. Bob and Hazel described leakage problems with their first appliances with Bob still experiencing these at three months:

"they tried three or four different bags and nothing was really successful until they put this high output bag on and that's been pretty good but we have still had set downs with it" (Bob, 3m).

For Hazel, this was compounded by feelings of bewilderment as to how different appliances worked, leading to early mistakes, which contributed to a loss of confidence. Involvement in decisions about appliance choice was described positively but loss of control and confidence with regard to practical stoma care were exacerbated when the selected appliance was not secure and professional support to provide a resolution to the problem was perceived to be lacking.

Leakage of the appliance threatened participants' sense of control. In hospital, it reinforced their dependence on nursing staff and fostered a perception that they would not be able to cope. Bob and Hazel spoke about feeling guilty for using the limited time of the ward nurses and Bob reported feeling humiliated having to rely on nurses to undertake care that he expected to be able to do himself. When experienced at home, a leaking appliance was viewed as a setback. Some experienced explosive and unmanageable incidents that were embarrassing and distressing:

"one morning I woke up and I thought 'this doesn't feel right' and I was in bed and the thing had all leaked; it was very traumatic; I was in a terrible state" (Ken, 3m).

Dependence on others to deal with any mess added to the distress. Hazel was distraught that her daughter had to stand her in the bath "like a child" $(3 \mathrm{~m})$. 
At nine months participants with persisting unsettled and unpredictable stoma function tended also to experience leakage problems. For Hazel this was so distressing she chose to stay at home rather than face situations that could potentially cause her embarrassment. Bob's continued appliance leakage at nine months made him feel "embarrassed, annoyed and frustrated" over his lack of bodily control.

\section{Altered bodily sensation}

In addition to changed appearance and disrupted bodily function, participants described altered bodily sensation following stoma formation, the predominant change being one of loss, rather than difference, in sensation. Some described knowing that their stoma was part of their body but being unable to feel anything when they touched it or when it discharged:

"seeing something like that working on your hip, you think they are going to hurt because they are very fresh and you see it move and you think oh this is weird; you think if you touch it it's going to be like painful because they look sore but you don't feel anything" (Maria, 3m)

Flora and Maria could only tell if their stoma had worked by feeling the weight of the appliance rather than a sensation of stoma function. Inability to feel a part of their own body when it was touched or when it functioned promoted a feeling of disconnection between body and self, echoing experiences of disrupted bodily appearance and function. However, the altered bodily sensation described at three months was not mentioned by any of the participants at nine or fifteen months, indicating that increasing familiarity with the stoma derived over this period may have diminished consciousness of the initial experience. Heightened consciousness of the appliance remained, however, when it was heavy with motion or causing irritation. Several participants enjoyed wearing no appliance, albeit for relatively brief periods: "I don't have anything on for about five, ten minutes; I just take the whole lot off because it just feels so nice for the air to get to the skin" (Ken, 9m). For some 
participants, the effect was to ascribe their feelings of consciousness about their changed bodies to the appliance rather than the stoma.

There were participants who accepted themselves with a stoma early in their postoperative journey, but this did not represent a return to the unconscious relationship between mind and body they experienced prior to their illness and surgery. While initially unfamiliar, Ellen and Laura identified their stomas as being "part of me" at three months and suggested that other people needed to accept them with a stoma. However, although Laura hoped for a time when she would experience her stoma unconsciously, she had not reached that stage even at fifteen months:

"hopefully over the course of time it [will] become more second nature; I don't think it's there yet; I think I'm still conscious of it at the moment; I don't know at what point I will forget it's there but I can see it's moving in that direction" (Laura, 15m).

Craig experienced pre-operative symptoms of ulcerative colitis that created a sense of alienation from his body through uncontrollable and unpredictable bowel function, forcing him to stay at home, "trapped like a caged animal" (Craig, 3m). His stoma-forming surgery contributed fundamentally to regaining the personal and bodily autonomy he had lost because of his ulcerative colitis and therefore facilitated his acceptance of his stoma: "my body movements and how I can react and you know, mentally in myself, I feel a lot more confident in what I am doing" (Craig, 3m). Maria, like Craig, welcomed the surgery and stoma as ridding her from intractable ulcerative colitis but even so they both stated that the main reason for opting for reconstructive surgery (without a stoma) was in order to feel 'normal' again.

\section{Discussion}

The experience of bodily change following stoma formation is rooted in the disconnection between a person's body and their sense of self prior to their surgery by making them acutely aware of the bodily changes created by it. Heightened awareness of changed bodily 
appearance, sensation and function has been noted [16, 18]. Kelly [9] further draws attention to the way individuals no longer experience their bodies unconsciously following panproctocolectomy and ileostomy. This resonates with the exploration of 'disembodiment' in the process of recovery following curative colorectal cancer [39]. The present study provides further evidence to support the findings of Kelly [9] and Taylor et al [39] and also demonstrates that heightened bodily awareness is experienced following other types of stoma-forming surgery. As Kelly's study was retrospective and Taylor et al [39] included only four people with a stoma in their sample, this study provides new understanding of the experience of heightened awareness of the changed body that alters over time.

Returning to how their bodies looked and functioned before the onset of their condition and subsequent stoma could signify a complete recovery. This longitudinal study highlights that a return to pre-operative normality is not always achieved as the awareness of the body that is necessary to exercise social autonomy challenges the ability to return to the unconscious 'normal' relationship between body and self. While existing research identifies the experience of feeling different following stoma-forming surgery $(29,13,10,19]$, there is little further exploration of what this may mean with regard to an individual's sense of self. This study examines how feeling 'different' related to perceptions of a changed body, an altered social world and experiences of healthcare. Madjar [40] argues that it is the loss of this familiar, unconsciously experienced body that signifies illness to the individual experiencing it with a profound need "to regain the familiar sense of the habitual body" (p57). Individuals therefore strive to be themselves again, to return to 'normal.' In returning to usual activities only some goals will be achievable due to the individual response to change in the embodied self that living with a new stoma involves.

People feel different about their bodies not only as a result of heightened awareness of their changed body but because their bodies with a stoma can be perceived as repulsive and alien, creating a rift between body and self. Although previous studies highlight ways in which stoma formation can create an alienation from the body $[10,16,18,14]$, this is only 
fully examined by Kelly [9]. White and Unwin [5] identified a feeling of being a complete person as the single most important factor in determining psychological morbidity following stoma formation, but they did not investigate what 'being a complete person' might mean. This initial rift in the sense of embodied self in an individual with a new stoma may gradually diminish over time providing they can regain mastery of their body and reconnection with their social world. Additionally, factors of time and bodily and social self-determination all contribute to gradual healing of this rift in the embodied self.

The need to master stoma management and predictability is fundamental to adaptation to a new stoma and the achievement of a balanced unity between body and self. Understanding of this experience is deepened by the exploration of how bodily mastery is achieved and experienced over a longer time-frame than used in previous studies, highlighting the centrality of relationships with healthcare staff responsible for building competence in stoma self-care. Experiences of appliance failure, unscheduled or audible bowel movements or a perception that others can see the stoma impinge on individuals' self-confidence and social function $[11,41,42]$. However, there is a lack of recognition of the importance of these elements of bodily mastery in supporting the development of self-confidence. A number of interpretive qualitative and positivist quantitative studies identify mastery over stoma care and feeling in control of the body following stoma formation as promoting adaptation to a new stoma [31, 5, 14, 18]. Only Kelly [9, 22] and McVey et al [17] investigate the relationship between bodily mastery and social functioning that was evident in the present study. The transferability of these previous studies is limited by a focus on specific diagnoses and limited follow-up, with Kelly [9] adopting a retrospective approach and McVey et al [17] exploring the experience of stoma formation for cancer prospectively but only up to three months following surgery. An interruption to general physical function, in particular pain and mobility, is most common in the immediate post-operative period [21, 29, 9, 17, 41] but what needs to be acknowledged more fully is that mastering general bodily function continues to 
impact on social reintegration for individuals with a new stoma at a year or more following their surgery.

\section{Embodiment and embodied self}

This study demonstrates that embodiment and embodied self are valuable concepts with which to make sense of the experience of living with a new stoma. A concept of embodiment suggests that when the body is limited, as in stoma formation, it is perceived to be encumbered and constrained, thus limiting the capacity of the self to operate within the freedoms it previously experienced [49]. Gallagher [50] and van Manen [51] propose that a true sense of embodied self is only restored by re-establishing the body as an unconsciously experienced aspect of self. Re-establishing body-self unity following bodily change can be argued to involve a process of mastering the body (viewed objectively), followed by a more $\underline{\text { balanced relationship between the objectively-viewed body and self, with an ultimate stage }}$ of unconscious body-self unity that individuals may or may not achieve [51].

Acceptance of the need to develop a new sense of self with a stoma appears to be central to the process of reconnecting body and self. As Madjar [40:60] suggests, "the only way forward [following a body-changing experience] has to involve the creation of a new kind of future and a constitution of self as a changed person." The re-connection of the body-self unity after stoma formation involves moving from the mastery of the body as object to establishing an enduring relationship between body and self. The process of reconnecting body and self following stoma formation is seen in this study to evolve over varying timescales, but re-establishing the body as an unconsciously experienced aspect of self had not been achieved by any participant at 15 months following their surgery.

\section{Strengths and limitations}

This research provides new insights into the experience of bodily change following stomaforming surgery. However, it is not possible to infer from the data that people with wider diagnoses than those included would draw similar meanings from their experiences. The 
importance of the expectations with which individuals approach their surgical experiences are highlighted; further research might usefully examine experiences of those who undergo emergency stoma formation with little or no advance preparation. As this study has shown time to be an essential aspect of the experience of living with a stoma, a longer time-frame for data collection could have permitted deeper exploration and understanding of adaptation to and acceptance of a changed sense of embodied self.

\section{Conclusion}

Stoma formation disrupts the unconscious relationship between body and self that for most exists before their surgery, making them feel different. Consciousness of changed bodily appearance, function and sensation creates a disconnection between body and self that influences the reactions of individuals with a new stoma to their bodily change, leading to negative feelings and attempts to distance themselves from their changed bodies in an effort to regain 'normality.' Time and a range of other facilitators can enable individuals to reconnect with and master their bodies, but the need to be aware of their stoma in order to care for it appropriately means that a return to the pre-operative unconscious relationship with their body is not possible. Some understand this change; others find it more difficult to accept. This study provides new knowledge of how the experience of heightened awareness of the changed body following stoma formation alters over time, and how a more nuanced understanding of feelings of being different can shape recovery goals, which centre on regaining normality. Such goals may or may not be achievable depending on the extent to which normality is defined by the individual as a return to their pre-stoma sense of embodied self. This increased knowledge and understanding provides patients, families and clinicians with actionable insight into the process of adjusting to life with a new stoma.

A concept of embodiment that encompasses body image, rather than a simple concept of body image alone, can enable the experience of living with a new stoma to be understood as part of a wider process of re-establishing a unity between body, self and world. This underlines the importance of understanding the experience of living with a new stoma not 
only from a person's reflective knowledge of the changes this brings, but also through their pre-reflective meaning-making actions.

\section{Declaration of Interest Statement}

This study was funded by a University of East Anglia full-time PhD Studentship and by a $£ 2000$ grant from The League of St Bartholomew's Nurses Isla Stewart Memorial Fund. The authors report no declarations of interest.

\section{References}

1. Elcoat C \& Frost S. Background to the High Impact Actions for Stoma Care. In Coloplast Ltd High Impact Actions for Stoma Care. Peterborough: Coloplast Ltd; 2010.

2. United Ostomy Associations of America [Internet] Welcome to the UOAA; 2015 [cited 2015 Jan 16]; Available from: http://www.ostomy.org/Home.html

3. Burch J. Exploring the conditions leading to stoma-forming surgery. British Journal of Nursing 2005;14(2):94, 96-8.

4. Klopp AL. Body image and self-concept among individuals with stomas. Journal of Enterostomal Therapy 1990;17(3):98-105.

5. White CA, Unwin JC. Post-operative adjustment to surgery resulting in the formation of a stoma: the importance of stoma-related cognitions. British Journal of Health Psychology 1998;3:85-93.

6. Piwonka M, Merino J. A multidimensional modelling of predictors influencing the adjustment to a colostomy. Journal of Wound, Ostomy and Continence Nursing 1999;26:298-305.

7. Pachler J, Wille-Jørgensen P. Quality of life after rectal resection for cancer, with or without permanent colostomy. Cochrane Database of Systematic Reviews 2005; Issue 2. Art. No.: CD004323. DOI: 10.1002/14651858.CD004323.pub3. 


\section{Thorpe G, McArthur M, Richardson B. Bodily change following faecal stoma formation:}

\section{qualitative interpretive synthesis. Journal of Advanced Nursing 2009;65(9):1778-1789}

9. Kelly M. Self, identity and radical surgery. Sociology of Health \& Illness 1992;14(3):390415.

10. Beitz JM. The lived experience of having an ileoanal reservoir: a phenomenologic study. Journal of Wound, Ostomy and Continence Nursing 1999;26(4):185-200.

11. Persson E, Hellström A-L. Experiences of Swedish men and women 6 to 12 weeks after ostomy surgery. Journal of Wound, Ostomy and Continence Nursing 2002;29(2):103-108.

12. Coe M, Kluka S. Concerns of clients and spouses regarding ostomy surgery for cancer. Journal of Enterostomal Therapy 1988;15:232-239.

13. Salter MJ. What are the differences in body image between patients with a conventional stoma compared with those who have had a conventional stoma followed by a continent pouch? Journal of Advanced Nursing 1992;17:841-848.

14. Rozmovits L, Ziebland S. Expressions of loss of adulthood in the narratives of people with colorectal cancer. Qualitative Health Research 2004;14(2):187-203.

15. Aron S, Carrareto R, Prazeres SMJ, Barbosa de Cerqueira AP, Conceio de G, Santos VL. Self-perceptions about having an ostomy: a post-operative analysis. Ostomy/Wound Management 1999;45(4):46-62.

16. Manderson L. Boundary Breaches: the body, sex and sexuality after stoma surgery. Social Science \& Medicine 2005;61:405-415.

17. McVey J, Madhill A, Fielding D. The relevance of lowered personal control for patients who have stoma surgery to treat cancer. The British Journal of Clinical Psychology 2001;40, 337-360. 
18. Annells M. The experience of flatus incontinence from a bowel ostomy: a hermeneutic phenomenology. Journal of Wound, Ostomy and Continence Nursing 2006;33(5):518-524.

19. Savard J, Woodgate R. Young people's experience of living with ulcerative colitis and an ostomy. Gastroenterology Nursing 2009;32(1):33-41.

20. Sutherland AM, Orbach CE, Dyk RB, Bard M. The psychological impact of cancer and cancer surgery: I. Adaptation to a dry colostomy; preliminary report and summary of findings. Cancer 1952;5(5):857-872.

21. Orbach CE, Tallent N. Modification of perceived body and of body concepts following the construction of a colostomy. Archives of General Psychiatry 1965;12:126-135.

22. Kelly M. Coping with an ileostomy. Social Science and Medicine 1991;33(2):115-125.

23. Deeny P, McCrea H. Stoma care: the patient's perspective. Journal of Advanced Nursing 1991;16:39-46.

\section{Thorpe G, McArthur M, Richardson B. Healthcare experiences of patients following} faecal output stoma-forming surgery: a qualitative exploration. International Journal of

\section{Nursing Studies 2014;51: 379-389}

25. Moran D. Introduction to phenomenology. London: Routledge; 2000.

26. Moustakas C. Phenomenological research methods. Thousand Oaks: Sage Publications; 1994.

27. Merleau-Ponty M. Phenomenology of Perception. London: Routledge; 1945, trans. C Smith 2002.

28. Thomas C, Madden F, Jehu D. Psychological morbidity in the first three months following stoma surgery. Journal of Psychosomatic Research 1984;28(3):251-257. 
29. Wade B. Colostomy patients: psychological adjustment at 10 weeks and 1 year after surgery in districts which employed stoma-care nurses and districts which did not. Journal of Advanced Nursing 1990;15:1297-1304.

30. Bekkers M, van Knippenburg F, van Dulmen A, van den Borne H, van BergeHenegouwen G. Survival and psychological adjustment to stoma surgery and non-stoma bowel resection: a four year follow up. Journal of Psychosomatic Research 1997;42:235244.

31. Bekkers M, van Knippenberg F, van den Borne H, van Berge-Henegouwen G.

Prospective evaluation of psychosocial adaptation to stoma surgery: the role of self-efficacy. Psychosomatic Medicine 1996;58:183-191.

32. Patton MQ. Qualitative research and evaluation methods. $3^{\text {rd }}$ ed. Thousand Oaks: Sage Publications; 2002.

33. Hesse-Biber SN, Leavy P. The practice of qualitative research. Thousand Oaks: Sage Publications; 2006.

34. Kvale S. Doing interviews. London: Sage Publications; 2007.

35. Colaizzi PF. Psychological research as the phenomenologist views it. In: Valle RS, King M, editors. Existential-phenomenological alternatives for psychology. New York: Oxford University Press; 1978.

36. van Manen M. Researching lived experience: human science for an action sensitive pedagogy. Albany: State University of New York Press; 1990.

37. Smith JA, Osborn M. Interpretive Phenomenological Analysis. In: Smith JA, editor. Qualitative psychology: a practical guide to research methods. $2^{\text {nd }}$ ed. London: Sage Publications; 2008. 
38. Angen M. Evaluating interpretive inquiry: reviewing the validity debate and opening the dialogue. Qualitative Health Research 2000;10(3):378-395.

39. Taylor C, Richardson A, Cowley S. Restoring embodied control following surgical treatment for colorectal cancer: a longitudinal qualitative study. International Journal of Nursing Studies 2010;47:946-956.

40. Madjar I. The body in health, illness and pain. In: Lawler J, editor. The body in nursing. Australia: Churchill Livingstone; 1997.

41. Sinclair LG. Young adults with permanent ileostomies: experiences during the first four years after surgery. Journal of Wound, Ostomy and Continence Nursing 2009;36(3):306316.

42. Andersson G, Engström Å, Söderberg S. A chance to live: women's experiences of living with a colostomy after rectal cancer surgery. International Journal of Nursing Practice 2010;16:603-608.

43. Williams J. Psychological considerations in gastrointestinal nursing. British Journal of Nursing 2005;14(17):931-935.

44. Noone P. Pre- and postoperative steps to improve body image following stoma surgery. Gastrointestinal Nursing 2010;8(2):34-39.

45. Price B. Body image: nursing concepts and care. London: Prentice Hall; 1990.

46. Price B. How to make an assessment of 'altered body image' in stoma patients. Eurostoma 1993;Autumn:14-15.

47. Toombs SK. Reflections on bodily change: the lived experience of disability. In: Toombs SK, editor. Handbook of Phenomenology and Medicine. Dordrecht: Kluwer Academic Publishers; 2001. 
48. Wilde M. Embodied knowledge in chronic illness and injury. Nursing Inquiry 2003;10(3): 170-176.

49. Leder D. The absent body. Chicago: University of Chicago Press; 1990

50. Gallagher S. Lived body and environment. In: Moran D, Embree L, editors.

Phenomenology: Themes and Issues Vol II. Abingdon: Routledge; 2004.

51. van Manen M. Modalities of body experience in illness and health. Qualitative Health Research 1998;8(1):7-24.

52. Tao H, Songwathana $\mathrm{P}$, Isaramalai S, Zhang Y. Personal awareness and behavioural choices on having a stoma: qualitative metasynthesis. Journal of Clinical Nursing

2013;23:1186-1200 